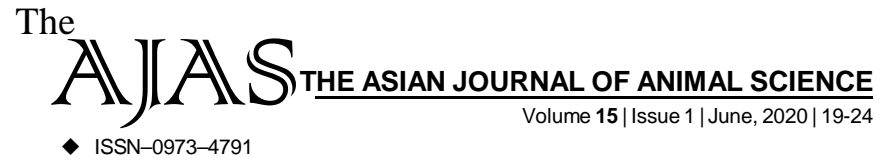

\title{
Identification of critical control points for street foods in Puducherry
}

S.B. Narayanan, V.J. Ajaykumar, Bhanu Rekha and Nithya Quintoil

Author for Corresponding -

\section{S.B. Narayanan}

Department of Veterinary Public

Health and Epidemiology, Rajiv

Gandhi Institute of Veterinary

Education and Research,

Puducherry (T.N.) India

Email: narayanan.sb@gmail.com
ABSTRACT...... Street food is a major attraction for tourists and natives of Puducherry and its popularity can be attributed to its variety and affordability. This study was undertaken to assess the critical control points for the street food available in Puducherry. Information was collected by interview and observation. Thirty outlets were visited and information on demographic data on vendors and hygienic practices during the production and dispensing of food items was collected. Drinking water and hand wash samples of vendors were collected and subjected to microbial analysis. It was found that 26.7 per cent were not aware of licensing and only one respondent had FSSAI registration. Raw leafy vegetables were not washed by 56.7 per cent vendors. Most of vendors (93.3\%) were handling food and collecting cash at same time, 70 per cent without washing hands in between. Same person handled food and waste at 73.3 per cent of shops, half of them only washed hands in between. Presence of coliforms were detected in 40 per cent of the drinking water samples and 100 per cent of hand wash water samples, indicating gross contamination. Results of study indicated that, handling of cash and food without washing hands in between, handling food as well as waste by same person at a time, less availability of quality water and use of unwashed raw leafy vegetables as critical control points of street food hygiene in Puducherry. The results show the need for bringing street food vendors together at different points in city so that availability of quality water and proper waste disposal can be ensured to improve the quality of street food. Also training these vendors in hygienic food preparation and handling is a must to overcome the lacunae in their existing knowledge level. Strict implementation of licensing for street food in Puducherry is essential to ensure food safety in street foods.

KEY WORDS....... Street food hygiene, Critical control points

HOW TO CITE THIS ARTICLE - Narayanan, S.B., Ajaykumar, V.J., Rekha, Bhanu and Quintoil, Nithya (2020). Identification of critical control points for street foods in Puducherry. Asian J. Animal Sci., 15(1): 19-24.DOI:10.15740/HAS/TAJAS/15.1/19-24.Copyright@2020:HindAgri-Horticultural Society.

ARTICLE CHRONICLE - Received : 10.02.2020; Revised : 06.05.2020; Accepted : 22.05.2020 